\title{
Identification of the best flood retrofitting scenario in an urban watershed by means of a Bayesian Decision Network
}

\author{
V. Notaro ${ }^{1}$, C. M. Fontanazza ${ }^{1}$, G. La $\operatorname{Loggia}^{2} \&$ G. Freni ${ }^{1}$ \\ ${ }^{I}$ Facoltà di Ingegneria ed Architettura, Università di Enna "Kore", Italy \\ ${ }^{2}$ Dipartimento di Ingegneria Civile, Ambientale, \\ Aerospaziale e dei Materiali, Università di Palermo, Italy
}

\begin{abstract}
Urban resilience to floods can be defined as a city's capacity to avoid damage through the implementation of structural and non-structural measures, to reduce damage in the case of a flood that exceeds a desired threshold, to recover quickly to the same or an equivalent state, and to adapt to an uncertain future. To build flood resilience, planners need to identify and analyse risk, to understand the impacts of flooding, and how they cope with these impacts by means of innovative and adaptable strategies and measures. The number of possible retrofitting scenarios to cope with flooding problems in an urban watershed could be greatly increased by the combination of several stormwater management practices. Therefore, the present study aims to develop an expert system in the form of a Bayesian Decision Network (BDN) able to evaluate the efficiency of some possible urban flood retrofitting scenario by examining all significant water management variables and their inherent uncertainty. The methodology was applied to an urbanized area of the city of Palermo (Italy).

Keywords: Bayesian Decision Networks, urban resilience, urban flooding, urban drainage modelling, flooding damage.
\end{abstract}

\section{Introduction}

Urban flooding can cause significant disruptions in cities, especially to housing, to industrial and commercial activities, to urban transportation, to public strategic facilities and to energy and water supply, leading to considerable 
impacts on people, on economy and on the environment. These impacts may be exacerbated by climate and socio-economic changes [1].

The Directive 2007/60/EC [2] prescribes that a preliminary flood risk assessment should be undertaken to provide an assessment of potential flood risks based on available or readily derivable information, such as records and studies on long term developments, in particular impacts of climate change on the occurrence of floods. On the basis of a preliminary flood risk assessment, those areas for which potential significant flood risks exist or might be considered likely to occur should be identified. For these areas, flood hazard maps and flood risk maps should be prepared; and on the basis of these maps, flood risk management plans including appropriate measures for the management of flood risks should be established, focusing on the reduction of potential adverse consequences of flooding and on the reduction of the likelihood of flooding.

In the past, flood risk management plans were usually based on the classical philosophy to cope with flooding by massive pipe network re-design campaigns improving the drainage capability of the system (building bigger pipes, improving surface collection system, etc.). Whilst this approach is successful in eliminating local flooding problems, the increased volumes and peak flows resulting from urbanization often cause downstream flooding problems together with pollution and erosion of natural receiving water bodies. Moreover, this approach is usually unpractical and anti-economical when dealing with large and complex drainage systems or with the older networks in strongly urbanized areas, such as the centre of some ancient municipalities. In such situations, sewer systems are often surcharged by stormwater and flooding occurs even with frequent rainfalls.

An alternative framework for urban flood hazard management could be the "urban resilience to floods". Resilience is a concept that has emerged as a way to understand how systems prepare for, respond to, and recover from shocks [3]. Although there are many different concepts of resilience, most authors are in agreement that a flood resilient city will have low flood consequences if and when flooding occurs [1]. Flood resilience is considered an important objective in flood risk management and a desirable attribute for cities [4]. However, several challenges remain for transforming the concept of resilience into an operational tool that can be used for policy and management purposes. If cities are to become more resilient to flooding, innovative and adaptable strategies and measures are needed. According to this concept, planners should identify and analyse risk, to understand the impacts of flooding, and how they cope with these impacts by means of innovative and adaptable strategies and measures. Many stormwater retrofit practices have been suggested along with other available watershed restoration strategies. Namely, stormwater retrofits consist of a series of structural practices, such as infiltration and storage ones, designed to reduce the peak flow of runoff, mitigate erosive flows, reduce pollutants in runoff, and promote conditions for improved aquatic habitat. The number of possible retrofitting scenarios for a given watershed could be greatly increased by the combination of several stormwater management practices. Different mitigation 
measures can interact in complex scenarios that mix the effect of two or more techniques. However, each solution can have advantages and disadvantages.

The analysis of urban planning is a preliminary mean to choose the scenarios achievable and different procedures could be used to test all the management options and choose the best among them. These procedures help to choose that scenario which maximizes cost-to-benefit ratio. A first step of this kind of analysis is usually based on the evaluation of the expected damage in the watershed related to a given flooding event by means of combining the flood depth-damage curves and the output of urban flood models [5, 6]. The application of advanced hydraulic models as diagnostic, design and decisionmaking support tools has become a standard practice in hydraulic research and application [7, 8]. Although mathematical models have been much improved in recent years, like all procedures based on a conceptualized representation of the real drainage system behaviour, its predictions are affected by a degree of inherent uncertainty [9-12]. Moreover, flooding damage functions are usually affected by significant uncertainty intrinsically related to the collected data and to the simplified structure of the adopted functional laws [6, 13]. As results flood damage evaluation is generally affected by a high level of uncertainty due to the accumulation of several uncertainty sources (e.g., intrinsic model uncertainty, uncertainty due to damage appraisal, etc.).

The previous considerations confirm the need of including uncertainty estimation in the process in order to identify the optimal flood mitigation solutions in terms of an integrated cost-benefit analysis. To this aim, the present study intends to develop an expert system in the form of a Bayesian Decision Network (BDN) able to examine all significant water management variables and their inherent uncertainty and to evaluate the efficiency of retrofitting scenarios in the reduction of flooding damage. The described methodology was applied to a highly urbanized area of the city of Palermo (Italy). A mathematical model, simulating the runoff formation and surface flooding propagation was adopted and calibrated to analyse the sewer system behaviour with respect to surface flooding generation and related damage.

\section{Materials and methods}

\subsection{Bayesian Decision Network}

Bayesian Networks (BN) are powerful interactive algorithms for decision making capable of describing and taking into account the inherent uncertainty in system knowledge [14]. In literature several applications of BNs have been proposed to find optimal decisions, control systems, or plans with regard to environmental problems and integrated water management issues [15-17].

A BN can be intended as a graphical model that combines elements of graph theory and probability theory. The analysed system is conceptualized by a directed acyclic graph (DAG), a graph without cycles, in which the nodes represent system variables, the arcs signify the existence of direct causal influences between the linked variables, and the strengths of these influences are expressed by forward conditional probabilities. In a BN, either dependent (i.e., 
related) nodes and independent (i.e., unrelated) nodes can be depicted and each node or variable may take one of a number of possible states or values.

BNs are a robust method to deal with uncertainty [17]. Namely, BNs are particularly useful for assessing risk and uncertainty and providing a framework for analysing cause and effect relationships in natural systems. Uncertainty is managed by adopting the Bayesian probability theory which is known to have a strong theoretical basis and to provide a unified approach compared to statistical and deterministic theories. According to Bayesian Rules, all possible values of each variable are defined in a BN through a probability distribution, called "marginal" distribution when expressed unconditionally, and the relationships between variables are explicitly expressed as conditional probability distributions [18]. Therefore, a BN can be easily updated as new knowledge about a system becomes available [19] and can be used for "reverse" inference (estimating the state of parent nodes given the state of child nodes). In this way, the state of the entire system can be estimated given changes in any part of it [15]. Moreover, an additional feature of BNs is their ability to combine both quantitative and qualitative data [20]. In a $\mathrm{BN}$, marginal and conditional probability distributions between variables can be estimated from either observed data, results from model simulations, or even expert judgment and other subjective information sources. This property is functional in those situations, like urban flooding analysis, where either the availability or reliability of the quantitative data are limited. To implement a reliable decision support tool considering effects of several stormwater retrofitting management options in a urban catchment, a particular BN was adopted in the present study: the Bayesian Decision Networks (BDN). The primary distinguishing features of a BDN are the inclusion of decision nodes (management option) and utility nodes (representing the utility related to a state variable in terms of cost-benefit). While state variable nodes are defined with a probability distribution across states, a decision node can only exist in one state at a time, representing a decision made between multiple choices. Each decision node contains a set of states that represent mutually exclusive management alternatives. Finally, a utility node provides a simple mean for estimating expected values of different outcomes: it is always a child node, and holds the benefits (or costs) that result from each state of its parent node. Figure 1 shows a conceptual framework for the BDN employed in the present study to identify the most suitable flood retrofitting scenario in the city centre of Palermo.

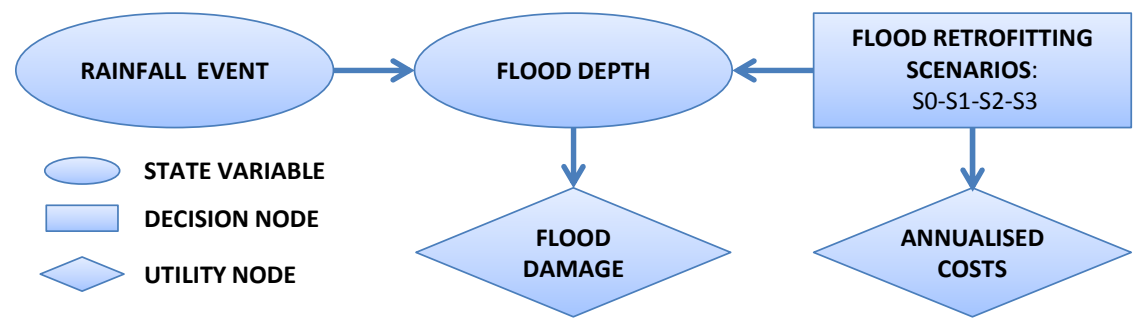

Figure 1: $\quad$ BDN model employed. 
This framework represents a five-nodes network including two state nodes (variables that describe the condition of the system) as well as a decision node (set of mutually exclusive watershed retrofitting management options) and two utility nodes (outcomes quantifiable in either economic or other terms that can be used to assess the success or failure of a decision). As shown in Figure 1, the decision node, Flood Retrofitting Scenarios (FRS), signifies several mutually exclusive flood management scenarios. It has two child nodes: the state variable Flood Depths (FD), representing the efficiency of the considered FRS state to mitigate flooding problems in the urban watershed for a given rainfall event and the utility node Annualized Costs (AC) expressing the implementation costs for the FRS state. The state variable Rainfall Event (RE) is included as another cause of FD while Flooding Damages (FDa) are the outcomes. By balancing AC and FDa the BDN model allows to identify the most suitable solution in terms cost-benefits.

\subsection{The mathematical model and related uncertainty}

The described BDN was applied to the oldest part of Palermo city (Italy), that is strongly urbanised and with a very old combined drainage system. The catchment receives wastewater and stormwater also from upstream less urbanized watersheds (Figure 2); local surface flooding due to the system insufficiency often occurs even for high-frequency rainfalls. Due to the system's surcharge, during 1993-2008, several parts of the watershed (circles in Figure 2) were affected by more than 30 flooding events for which by querying fire brigades and insurance companies an accurate database about flooded area, water depth and volume, duration and damaged properties have been implemented [6].

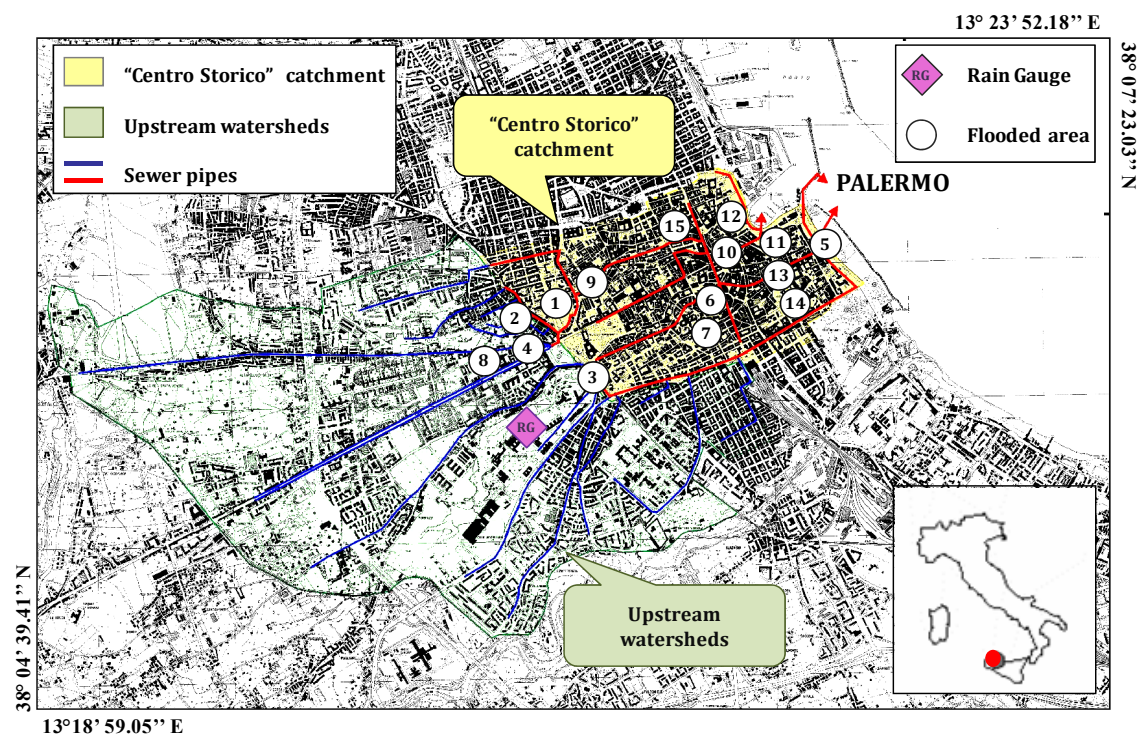

Figure 2: The "Centro Storico" catchment, with flooded areas. 
Inside the analysed area is located the Parco d'Orléans rain gauge, operational since 1993 with a temporal resolution of 1 minute. To simulate the urban drainage-system behaviour, in the present study, a numerical model based on the SWMM software and adopting a dual drainage approach [8] was adopted. Calibration was carried out on flood levels and volumes measured by Municipal Fire Brigades during ten of the recorded rainfall events [6].

In order to evaluate the uncertainty related to model parameters a Bayesian Monte Carlo analysis (BMC) was carried out. According to all Bayesian approaches, model parameters were treated as stochastic variables associated to probability distributions: uniform distributions were selected as prior probability distributions for all parameters because no information was available at the beginning of the study. To guarantee a consistent analysis that avoids any subjectivity, parameter variation ranges were assumed as the intervals that strictly include the calibrated values. The BMC analysis was based on the analysis of 1000 random parameter sets. Details about the uncertainty analysis carried out can be found in Fontanazza et al. [11].

\section{Methodology application and results analysis}

\subsection{Decision node: flood retrofitting scenarios (FRS)}

Due to the frequent flooding problems affecting the analysed watershed, some stormwater retrofitting measures have been proposed to improve the system performance. According to the specific local context, the presence of a dense urbanization and a considerable vehicle traffic, alternatives such as drainage wells, infiltration trenches or pervious pavements were rejected because requiring numerous building sites distributed all over the catchment. Centralised measures aimed to reduce the runoff peak flow, such as the diversion of stormwaters arriving from upstream watersheds and the construction of underground storage units were preferred. Three different flood retrofitting scenarios were analysed and compared with the actual scenario (Scenario 0 - no retrofitting measure) to identify the most suitable solution (Figure 3).

Scenario 1 simulates the diversion of most of stormwater volumes arriving from the upstream watersheds; the diverted volumes are sent to a neighbouring existing channel $3300 \mathrm{~mm}$ in size (marked conduit in figure 3a). Scenario 2 proposes the construction of three storage units (A, B and C in Figure 3b), and the change of slope and cross section for some conduits connected to these storage units, in order to allow gravity operation mode. The storage unit A receives part of stormwater volumes arriving from the upstream watersheds and has a volume of $4,000 \mathrm{~m}^{3}$; the storage units $B$ and $C$ have a volume of $15.000 \mathrm{~m}^{3}$ and $5,000 \mathrm{~m}^{3}$, respectively, and are located in the downstream area of the urban watershed to improve the hydraulic performance of the zones where the most critical surface flooding has been observed. Scenario 3 can be intended as a synthesis of the previous two simulating both the diversion of the upstream water volumes by a $3300 \mathrm{~mm}$ diameter conduit and the construction of the storage units B and C. Each proposed FRS was implemented in the hydraulic model of the urban drainage system. 


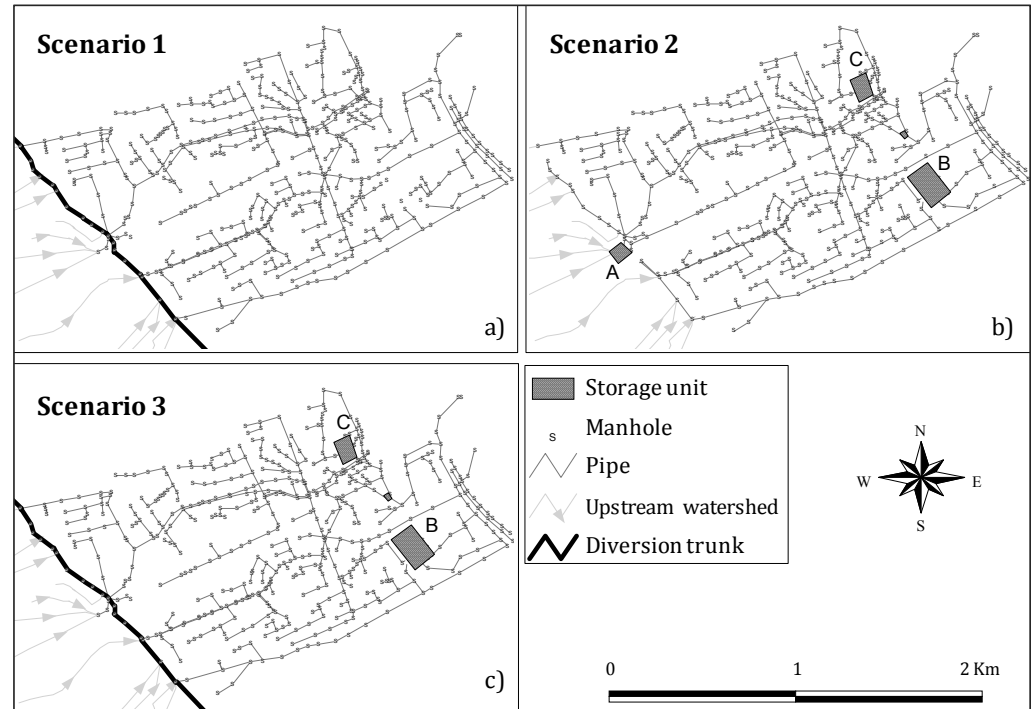

Figure 3: $\quad$ Schematic view of the three proposed retrofitting scenarios (FRS).

\subsection{Utility node: Annualised costs (AC)}

In order to assess the AC related to each proposed FRS, an economic analysis based on the Whole Life Costing method was performed. WLC provided a framework for the calculation of both capital and long-term maintenance costs, annualized over 50 years, associated with each individual flood retrofitting scenario. As a result an Annualized cost of M€ 0.472, M€ 0.394 and M€ 0.765 was applied respectively to Scenario 1, 2 and 3 if the related state was YES, on the contrary a cost of 0 was assessed to the NO state.

\subsection{Variable state: rainfall events (RE)}

The analysis of 2340 historical rainfall events, recorded during 1994 and 2008 at the Parco d'Orléans rain gauge, drove the selection of 1370 statistically independent rainfall events with a minimum inter event time of 7 hours. Those events were used as input for the hydraulic model of the drainage system.

\section{Results analysis}

\subsection{Flooding conditional probability distributions: RE - FRS $\rightarrow$ FD}

Each proposed FRS was simulated for all 1370 RE. Then, for each identified flooded location, the simulated FD was statistically processed obtaining the flooding frequency curves (conditional probability distributions) with the related uncertainty boundaries ( $5^{\text {th }}$ and $95^{\text {th }}$ quantiles). The analysis of Figure 4 
representing the response of the largest flooded area in the upstream part of the catchment (location 1 in Figure 2) allows the following considerations:

- the introduction of a new sewer pipe able to divert the most of upstream stormwater volumes (Scenario 1) reduces flood frequency; the effect is more relevant on frequent flooding and it is progressively less important with the increase of flooding return period due to the reduction both of the system efficiency to intercept upstream runoff and of the hydraulic capacity of the new sewer pipe;

- uncertainty is also reduced in Scenario 1 because the most of the upstream volume is diverted to the new sewer pipe and accordingly the uncertainty in runoff estimation is transferred to the sewer pipe model;

- the introduction of storage tanks in the system (Scenario 2) has a smaller impact on flooding in location 1 especially for higher return periods; uncertainty linked to flooding depth is slightly reduced with respect to Scenario 0 especially for more frequent flooding;

- location 1 shows the same response with regard to Scenario 1 and 3 thus confirming that the floods in this location are mainly due to local surcharging of the sewer system caused by upstream stormwater runoff.

The analysis of flooding frequency related to location 5 in the downstream part of the system (Figure 5), allows the following considerations:

- flooding depths and frequencies are marginally affected by the introduction of the new sewer pipe upstream (Scenario 1); this is mainly due to the fact that flooding downstream is mainly due to local system failures and to runoff generated in the central part of the watershed;

- uncertainty in Scenario 1 is slightly reduced by the introduction of the new pipe because it is mainly due to the uncertainties in the estimation of local runoff;

- the introduction of local storage tanks (Scenarios 2 and 3) has a major impact on flooding that is almost eliminated in the analysed location for return periods lower than 10 years; uncertainty is highly reduced because flooding depth absolute values are much lower than in Scenario 0 and the proximity of flooding to mitigation measures transfers the uncertainty on the storage tanks filling process.

As a general conclusion, with regard to the hydraulic performance of the drainage system, only Scenario 3 was able to efficiently reduce flooding both upstream and downstream. Moreover, uncertainty in flooding frequencies after the application of mitigation scenarios is dependent both on the absolute reduction of flooding depth and on the distance between flooding location and mitigation measure. This behaviour is due to the local runoff component that introduces uncertainty on the path between the retrofitting measure and the flooding location. In order to have an efficient decision tool for selecting the best mitigation scenario, an economic analysis is needed.

\subsection{Damage conditional probability distribution: UFD $\rightarrow$ FD}

To build the conditional probability distribution of the expected flood damage (FDa) were applied the depth-damage curves estimated in a previous study for 


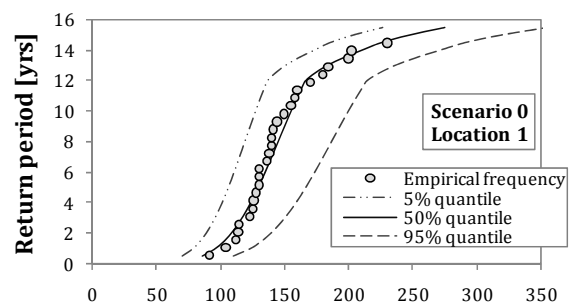

Flooding depth [cm]

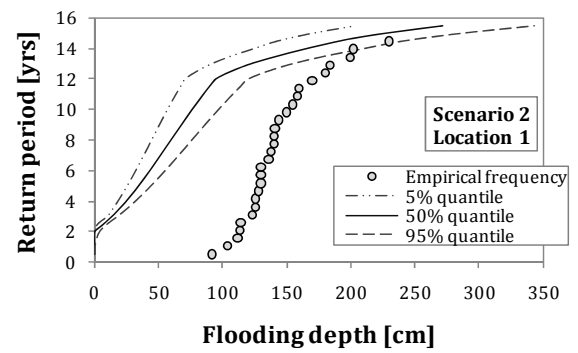

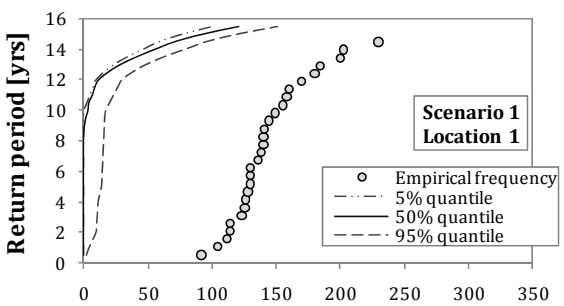

Flooding depth [cm]

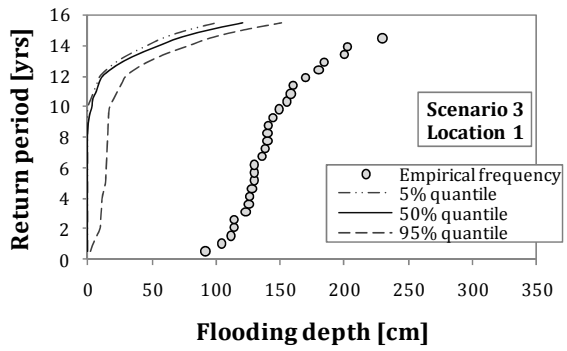

Figure 4: Frequency distributions of flooding depth estimated for each FRS in an upstream location (circle 1 in Figure 2) of the catchment.

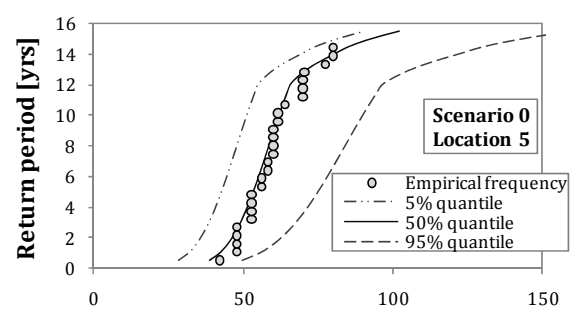

Flooding depth $[\mathrm{cm}]$

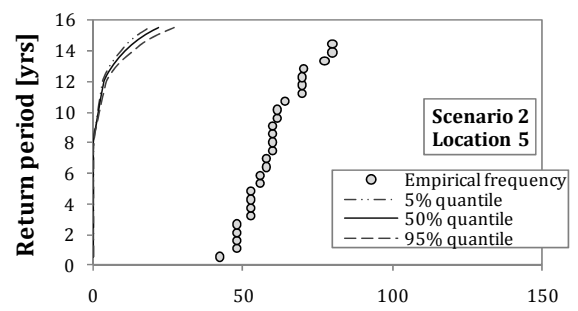

Flooding depth [cm]

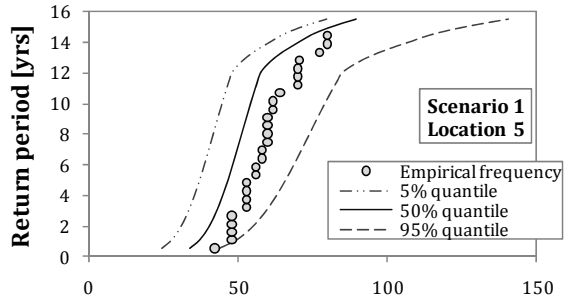

Flooding depth [cm]

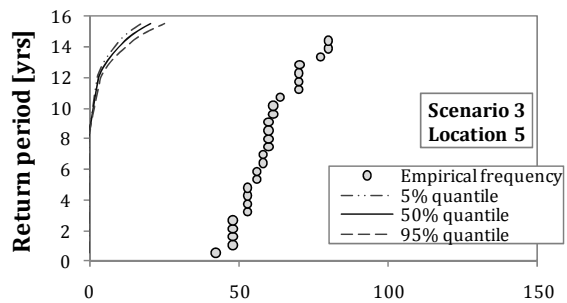

Flooding depth [cm]

Figure 5: $\quad$ Frequency distributions of flood depth estimated for each FRS in a downstream location (circle 5 in figure 2) of the watershed. 
the same watershed (Figure 6). Red lines, in figure 6, represent $5^{\text {th }}$ and $95^{\text {th }}$ quantiles of the 25 curves obtained by excluding data derived from one flooding location (identified by circles in figure 2) or from one flooding event [6].

Figure 7 reports the expected damage frequency distribution at catchment scale considering the uncertainty on flooding depth estimation (showed in Figures 4 and 5) and in damage estimation (reported in Figure 6).

In all FRS, uncertainty in damage estimation is reduced because part of the original uncertainty is transferred to the estimation of the diverted flow rate or the stored volumes in the tanks. This does not mean that the overall model uncertainty is reduced but simply that uncertainty refers to the estimation of different variables.

Scenario 3 seems the most convenient solution because, independently from the return period, the related expected damage is lower than the expected damage in Scenario 0 reduced of the related $\mathrm{AC}$ of the mitigation measures (M€ 0.765).
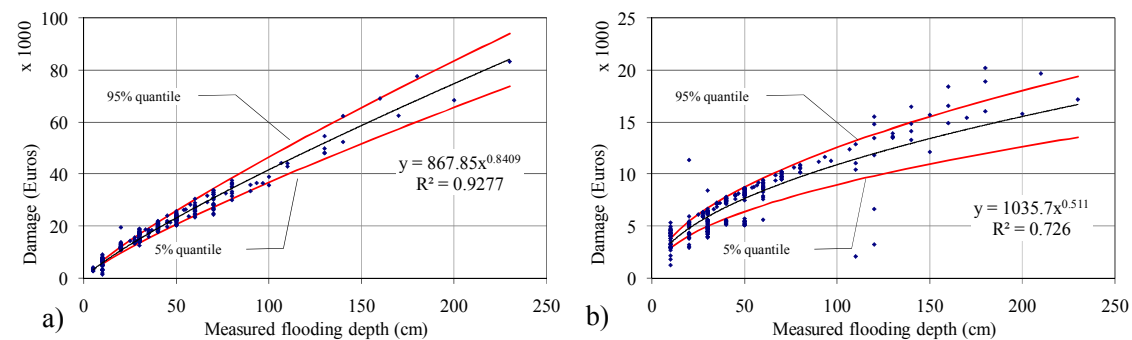

Figure 6: Depth-damage curves for building furniture a) and vehicles b) [6].
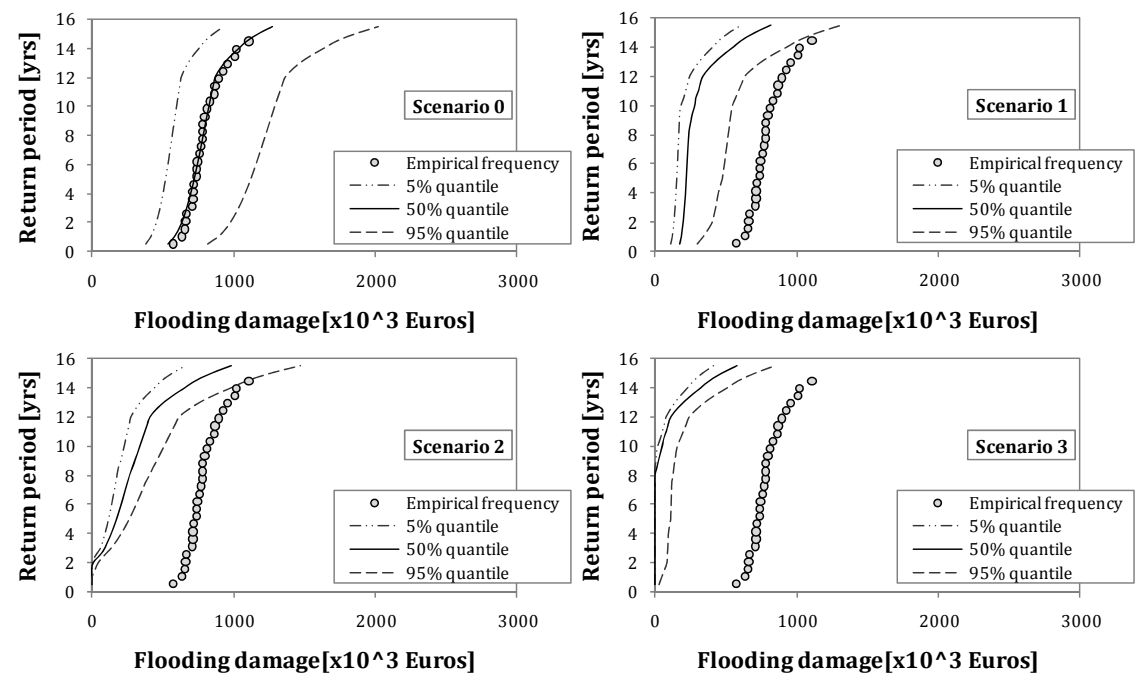

Figure 7: Frequency distributions of expected flooding damage at watershed scale for each FRS. 
Moreover, uncertainty in the estimation of expected damage is reduced if Scenario 3 is selected thus making this choice more robust than others.

Scenarios 1 and 2 provide interesting results but only for the lower return periods: taking into account the additional costs of the mitigation measures (M€ 0.472 for Scenario 1 and M€ 0.394 for Scenario 2), the impact of high return period flooding is larger than the actual condition. Those scenarios are characterised by an increasing uncertainty with the event return period. This aspect has to be taken into account considering that, provided the mitigation costs and the worst case for flooding damage $\left(95^{\text {th }}\right.$ quantile - upper uncertainty band), high return period events may generate overall costs higher than the expected damage in Scenario 0.

\section{Conclusions}

The present paper applied Bayesian Decision Networks for the estimation of urban flooding damage and for the selection of the most appropriate mitigation scenario. Bayesian Network in an uncertain context demonstrated to be its powerful tool thanks to their ability to analyse the most probable behaviour of the system and the uncertainty bands related both to the modelling estimation of flooding depth and of the depth - damage curves. The analysis demonstrated that different retrofitting scenarios have different impacts on expected damage and on related uncertainty so that, in some of the analysed cases, the uncertainty bands after the application of retrofittiing measures still contains the measured historical damage. This means that damage higher than the historical one for a specific return period is still possible even if less probable than in the "do nothing" scenario (Scenario 0). The study demonstrated that uncertainty estimation is an important component of the decision process especially in cases where mitigation scenarios provide comparable average results.

\section{References}

[1] Hammond M.J., Chen A.S., Djordjević S., Butler D. \& Mark O. 2013. Urban flood impact assessment: A state-of-the-art review. Urban Water Journal, DOI: 10.1080/1573062X.2013.857421

[2] Directive 2007/60/EC of the European Parliament and of the Council of 23 October 2007 on the assessment and management of flood risks.

[3] Zhou H., Wang J., Wan J., \& Jia H. Resilience to natural hazards: a geographic perspective. Natural Hazards, 53, pp. 21-41, 2010.

[4] Godschalk, D.R. Urban hazard mitigation: creating resilient cities. Natural Hazards Review, 4, pp. 136, 2003.

[5] Jonkman S.N., Bočkarjova M., Kok M. \& Bernardini P. Integrated hydrodynamic and economic modelling of flood damage in the Netherlands. Ecological Economics, 66 pp. 77-90, 2008.

[6] Freni, G., La Loggia, G., Notaro, V. Uncertainty in urban flood damage assessment due to urban drainage modelling and depth-damage curve estimation. Water Science \& Technology 61(12) pp. 2979-2993, 2010. 
[7] Mark O., Weesakul S., Apirumanekul C., Boonya Aroonnet S. \& Djordjević S. Potential and limitations of 1D modelling of urban flooding. Journal of Hydrology, 299 (3-4) pp. 284-299, 2004.

[8] Leandro, J., Chen A.S., Djordjević, S. and Savić, D.A. A comparison of 1D/1D and 1D/2D coupled (sewer/surface) hydraulic models for urban flood simulation. Journal of Hydraulic Engineering 135(6), pp.495-504, 2009.

[9] Gupta H. V., Beven K. J. \& Wagener, T.. 142: Model Calibration and Uncertainty Estimation". Encyclopedia of Hydrological Sciences. Edited by M. Anderson. C John Wiley \& Sons, Ltd., 2005.

[10] Fontanazza C. M, Freni G., La Loggia G. \& Notaro V. Uncertainty evaluation of design rainfall for urban flood risk analysis. Water Science \& Technology 63(11) pp. 2641-2650, 2011.

[11] Fontanazza C.M., Freni G., Notaro V (2012). Bayesian inference analysis of the uncertainty linked to the evaluation of potential flood damage in urban area. Water Science \& Technology 66(88), pp. 1669-1677.

[12] Notaro V., Fontanazza C.M., Freni G., Puleo V. Impact of rainfall data resolution in time and space on the urban flooding evaluation. Water Science \& Technology 68(9) pp 1984-1993, 2013.

[13] Notaro V., De Marchis M., Fontanazza C.M., La Loggia G., Puleo V. \& Freni G. The effect of damage functions on urban flood damage appraisal. Proc. of the $12^{\text {th }}$ Int. Conf. on Computing and Control for the Water Industry, Proceedia Engineering, Elsevier: Perugia, Italy, 2013, (in press).

[14] Cowell R.G., Dawid A.P., Lauritzen S.L., Spiegelhalter D.J. Probabilistic Networks and Expert Systems. Statistics for Engineering and Information Science. Springer-Verlag, New York., 1999.

[15] Sadoddin A., Letcher R.A. \& Newham L.T.H. A Bayesian decision network approach for assessing the ecological impacts of salinity management. Mathem. and Computers in Simulation 69(1-2), pp. 162-176, 2005.

[16] Fermani R., Henriksen H.J. \& Savich D. An evolutionary Bayesian belief network methodology for optimum management of groundwater contamination. Environmental Modelling \& Software 24, pp. 303-310, 2009.

[17] Aguilera P.A., Fernández A., Fernández R., Rumí R. \& Salmerón A. Bayesian networks in environmental modelling. Environmental Modelling \& Software 26, pp.1376-1388, 2011.

[18] Varis O. \& Kuikka S. Learning Bayesian decision analysis by doing: lessons from environmental and natural resources management. Ecological Modelling 119, pp. 177-195, 1999.

[19] Castelletti A. \& Soncini-Sessa R. Bayesian networks and participatory modelling in water resource management. Environmental Modelling and Software 22 (8), pp. 1075-1088, 2007.

[20] Ames D.P. \& Nielson B.T. Using Bayesian networks to model watershed management decisions: an East Canyon Creek case study. Journal of Hydroinformatics 7 (04), pp. 267-282, 2005. 